\title{
Metabolic response to fasting as affected by late gestation nutrition and selection line in lambs*
}

\author{
S. Husted, M.P. Tygesen and M.O. Nielsen ${ }^{1}$ \\ Department of Animal and Veterinary Basic Sciences, The Royal Veterinary and Agricultural University \\ Grønnegårdsvej 7, DK-1870 Frederiksberg C, Denmark
}

\begin{abstract}
The effects of 1 . feeding level (norm versus $60 \%$ of norm) during late gestation, and 2 . seletion line (daily weight gain versus carcass meat content) on subsequent metabolic adaptability to a 24 $\mathrm{h}$ fasting period in 10 week old lambs were studied. Higher glucose levels were maintained during fasting in lambs nutritionally restricted pre-natally, but NEFA levels increased more compared to non-restricted lambs. Foetal metabolic programming thus seem to be associated with more labile adipose tissue pools. Selection for carcass meat content induced similar changes in metabolic adaptability as foetal nutritional restriction, and the effects seemed to be additive.
\end{abstract}

KEY WORDS: metabolic programming, foetal, glucose, challenge, NEFA

\section{INTRODUCTION}

Substantial evidence now suggests that prenatal nutritional restriction during sensitive periods may result in so-called metabolic programming (Godfrey and Barker, 2000). The mechanisms of metabolic programming include different glucose sparing mechanisms (Desai and Hales, 1997) and changes in synthesis and sensitivity towards central hormones like insulin, growth hormone, IGF-1, T3/T4 and leptin (Desai et al., 1997; Heasman et al., 1999; Godfrey and Barker, 2000). Foetal malnutrition may therefore permanently affect the metabolic adaptability to variations in nutrient supply, and hence animal productivity.

In the present experiment it was the purpose to investigate whether metabolically programmed lambs would exhibit different metabolic responses to a $24 \mathrm{~h}$ fasting period compared to non-programmed lambs. And further whether

\footnotetext{
* Supported by the Danish Agricultural and Veterinary Research Council

${ }^{1}$ Corresponding author: e-mail: mon@kvl.dk
} 
genetic selection for growth rate versus meat content in the carcass (leanness) would affect this metabolic programming and adaptability.

\section{MATERIAL AND METHODS}

All experimental procedures were approved by The National Committee on Animal Experimentation, Denmark.

Experimental animals. 40 Shropshire lambs were used. They were born to 20 ewes, all pregnant with twins, and evenly distributed on two different selection lines and pre-partum feeding levels.

Feeding and experimental design. $2 \times 2$ factorial design with 2 selection lines: high daily weight gain (GROWTH) versus high slaughter quality (MEAT), and 2 different feeding levels offered to pregnant dams during the last 6 weeks prepartum: according to Danish requirements for energy and protein (NORM) or $60 \%$ of norm for net energy intake (LOW). Post-partum all dams and lambs were fed the norm diet ad libitum. Lambs were weaned 8 weeks post-partum.

Experimental procedures. Blood samples were taken by venipuncture at day 0 (3 h post-partum), 3, 7, 14, 21, 28, 70 and 140 post-partum. At 10 weeks of age, lambs were subjected to a $24 \mathrm{~h}$ fasting period, and blood samples was drawn from indwelling temporary catheters at time 0 (fed state), 6, 12, 18, 24 (fastedstate), and at 25 and $32 \mathrm{~h}$ (re-fed state). Wako NEFA C kit (Neuss, Germany) and Glucose kit Ecoline 100 (Darmstadt, Germany) were used for analysis of plasma NEFA and glucose, respectively.

Statistical analyses. Data were analysed as repeated measurements by the mixed model procedure in SAS version V8 (SAS Institute Inc., Cary, NC 275132414 , USA) with random effects of individual lambs using the following model with subsequent reduction of non-significant terms: NEFA = pre-partum feeding level $\mid$ selection line $\mid$ gender $\mid$ time. All values are given as LSMEANS $\pm \mathrm{SEM}$.

\section{RESULTS}

Birth weights of NORM lambs $(3.95 \pm 0.12 \mathrm{~kg})$ were significantly higher than LOW lambs $(3.15 \pm 0.12 \mathrm{~kg} ; \mathrm{P}<0.0001)$.

We could not establish any systematic effects of late gestation feed restriction nor selection line on basic plasma NEFA or glucose concentrations at any age from 0 to 140 days (results not shown). Except for right after birth ( $3 \mathrm{~h}$ post-partum), where very high plasma levels of NEFA and very low levels of glucose generally were observed. This was more pronounced in MEAT compared to GROWTH lambs.

As shown in Figure 1, NEFA concentrations were found to increase more in LOW compared to NORM lambs $(\mathrm{P}=0.0013)$ when subjected to a $24 \mathrm{~h}$ fasting period at 10 weeks of age. MEAT lambs had significantly higher NEFA 
concentrations after $12 \mathrm{~h}$ fasting compared to GROWTH lambs $(\mathrm{P}=0.037)$. Highest NEFA responses were obtained in the LOW-MEAT group.

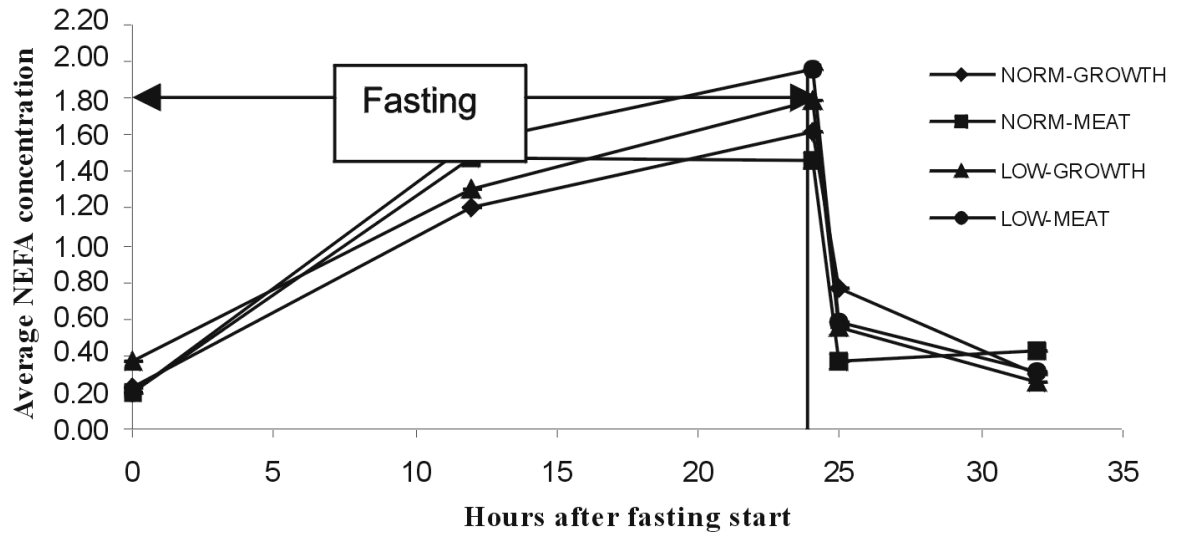

Figure 1. NEFA concentrations in plasma during fasting (0-24 h) and re-feeding (at $24 \mathrm{~h}$ ) in 10 week old lambs as affected by pre-partum feeding level and selection line

Larger drops in glucose concentrations were observed in GROWTH lambs in response to $24 \mathrm{~h}$ fasting compared to MEAT lambs, as shown in Figure 2, and it was especially pronounced in GROWTH lambs, whose mothers were NORM fed during late gestation. At $18 \mathrm{~h}$ glucose concentrations were significantly lower in the NORMGROWTH compared to LOW-MEAT lambs $(\mathrm{P}=0.010)$ and at $24 \mathrm{~h}$ the NORMGROWTH had lower concentrations than both NORM-MEAT and LOW-MEAT lambs ( $\mathrm{P}=0.017$ and $\mathrm{P}<0.0001$, respectively). Of the MEAT lambs, the LOW-MEAT group was the most efficient in maintaining glucose homeostasis during fasting.

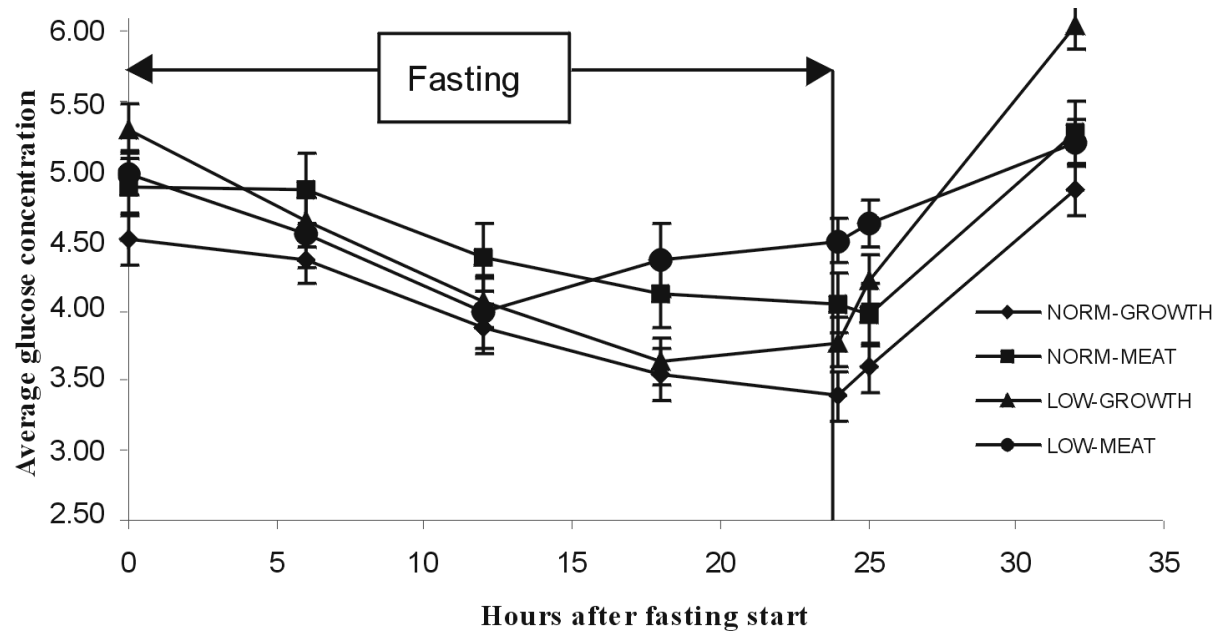

Figure 2. Glucose concentrations in plasma during fasting (0-24 h) and re-feeding (at $24 \mathrm{~h}$ ) in 10 week old lambs as affected by pre-partum feeding level 


\section{DISCUSSION}

Metabolic challenge associated with birth or during fasting, exposed differences in metabolic set-up between lambs of different genetic background, and between lambs exposed to different levels of nutrition pre-partum.

As expected, the pre-natal nutrient restricted lambs maintained higher glucose levels during fasting, presumably as a result of the described glucose sparing mechanisms associated with metabolic programming (Desai and Hales, 1997), including lower capacity for insulin secretion and tissue sensitivity for insulin (Godfrey and Barker, 2000). Therefore LOW lambs were expected to be exposed during fasting to smaller changes in endocrine factors responsible for adipose tissue mobilization. But surprisingly NEFA concentrations changed more during fasting and refeeding in LOW compared to NORM lambs, indicating that adipose tissue pools were just as or even more labile in LOW compared to NORM lambs. Metabolic programming may thus increase adipose tissue sensitivity towards other hormones like e.g., catecholamines.

Our findings suggest that genetically lean animals respond metabolically similar to fasting as metabolically programmed animals and that the effects are additive.

\section{CONCLUSIONS}

The regulatory changes associated with metabolic programming, which aids to limit energy expenditure later in life (Jackson et al., 1996), seem to primarily affect tissues other than the adipose. This may explain the predisposition of metabolically programmed animals for development of adiposity.

Therefore intriguing that selection for high carcass meat content (leanness) appeared to induce similar changes in metabolic adaptability to fasting as induction of foetal metabolic programming. This needs to be looked further into.

\section{REFERENCES}

Desai M., Byrne C.D., Meeran K., Martenz N.D., Bloom S.R., Hales C.N., 1997. Regulation of hepatic enzymes and insulin levels in offspring of rat dams fed a reduced-protein diet. Amer. J. Physiol. - Pt 1, 273, G899-G904

Desai M., Hales C.N., 1997. Role of fetal and infant growth in programming metabolism. Biol. Rev. Cambridge Phil. Soc. 72, 329-348

Godfrey K.M., Barker D.J.P., 2000. Fetal nutrition and adult disease. Amer. J. Clin. Nutr. 71, 1344S$1352 \mathrm{~S}$

Heasmann L., Clarke L., Stephenson T.J., Symonds M.E., 1999. The influence of maternal nutritient restriction in early to mid pregnancy on placental and fetal development in sheep. Proc. Nutr. Soc. $58,283-288$

Jackson A.A., Langley-Evens S.C., McCarthy H.D., 1996. Nutritional influence in early life upon obesity and body proportions. Ciba Foundation Symposium 201, 118-129 